\title{
Meio ambiente e interdisciplinaridade: desafios ao mundo acadêmico
}

\section{The environment and interdisciplinarity: challenges to the academic world}

\author{
Marcel BURSZTYN*
}

\section{RESUMO}

A produção acadêmica do conhecimento nos dois últimos séculos foi marcada por uma clara tendência especializante. A questão ambiental, vista pela ótica do desenvolvimento sustentável e que assume considerável relevância no presente, introduz mudanças significativas neste cenário e aponta para a necessária abordagem interdisciplinar (des-especialização). Utilizando exemplos da produção científica brasileira, a partir de dados do CNPq e Capes, o texto apresenta um perfil dos cursos de Pós-Graduação do país voltados ao tratamento da questão ambiental. Uma análise crítica do processo é evidenciada, bem como importantes limitações e desafios que se apresentam para a construção deste novo campo do conhecimento.

Palavras-chave: questão ambiental, desenvolvimento sustentável, interdisciplinaridade, formação acadêmica, Brasil.

\begin{abstract}
Academic production of knowledge in the past two centuries was marked by a clear specialization trend. The environmental issue, seen through the lenses of sustainable development, having currently acquired a considerable importance, introduces significant changes in this scenario and points to the need for an interdisciplinary approach (de-specialization). Using examples taken from the Brazilian scientific production, based on data provided by $\mathrm{CNPq}$ and Capes, this text draws a profile of graduate programs addressing the environmental issue, nationwide. A critical analysis of the process is highlighted, as well as the important limitations and challenges incurred in building this new field of knowledge.

Key-words: environmental issue, sustainable development, interdisciplinarity, academic education, Brazil.
\end{abstract}

* Doutor em Desenvolvimento Econômico e Social, professor da Universidade de Brasília (Departamento de Sociologia e Centro de Desenvolvimento Sustentável).
Foi presidente da Fundação de Apoio à Pesquisa do Distrito Federal - FAPDF e da Coordenação de Aperfeiçoamento de Pessoal de Nível Superior - Capes/MEC. 
A institucionalização do tema meio ambiente, vista pela ótica do desenvolvimento sustentável, ${ }^{1}$ como foco de formação específica na Universidade é bem recente. Tratase de fenômeno que não está limitado ao Brasil: em toda parte o mesmo movimento se repete.

O mundo universitário reproduz uma tendência semelhante ao mundo das políticas públicas: quando algo novo e relevante surge num determinado contexto, logo se propaga, num movimento em onda. Assim, a Universidade, que ao longo do século XX seguiu uma trajetória crescentemente especializante, desperta, ao final do século, para a necessária revisão de sua trajetória, diante do desafio de cumprir seu papel universalizante, de oferecer novas respostas às novas perguntas que o mundo real apresenta.

É dentro dessa moldura que a questão ambiental emerge como foco de interesse no mundo acadêmico. Quase que simultaneamente, em várias partes do Planeta surgiram espaços de pesquisa e formação voltados ao tema que se consagrara no calor dos alertas sobre explosão demográfica, poluição industrial e estrangulamento da oferta de energia. A pauta fora dada por uma combinação de circunstâncias: balanços acadêmicos catastrofistas; grandes acidentes industriais; emergência de um novo pólo de movimentos sociais (o ambientalismo) centrados em teses pacifistas e em demandas por uma melhor qualidade de vida; sucessivas mobilizações em torno de debates promovidos por organismos multilaterais, com destaque para a Conferência de Estocolmo, de 1972.

Como reflexo da demanda por soluções científicas e técnicas aos novos desafios identificados, alguns campos das ciências se mobilizaram.

A análise da vinculação dos temas ambientais como foco de interesse das pesquisas nas universidades e instituições de pesquisa em geral, no Brasil, pode ser situada no universo temporal de duas décadas. A base de dados disponível mais antiga é o Selap - Sistema em Linha de Acompanhamento de Projetos, do CNPq, cuja última atualização é de 1985. Embora se trate de informações a serem citadas com certa precaução, por não englobarem a totalidade de pesquisadores do País e por se valerem de meios de coleta de dados não totalmente confiáveis, o sistema pode ser tomado como base de referência. São 54 mil pesquisadores cadastrados, vinculados a 36 mil projetos (BURSZTYN, 1990).

De acordo com aquelas informações, o total de pesquisas que se identificavam como Meio ambiente e recursos naturais era de 580, distribuídas nas seguintes categorias:

- Recursos naturais - 139

- Estudos integrados dos ecossistemas - 51

- Estado ambiental - 87

- Áreas protegidas 17

- Poluentes - 11

- Dispersão e circulação de poluentes - 33

- Poluição - 123

- Métodos indiretos de controle da poluição - 65

- Direito ambiental e legislação - 26

- Educação ambiental e formação de recursos humanos -8

- Sistemas de informação em meio ambiente e recursos naturais -20

Os números acima revelam que em 1985 havia uma grande concentração da pesquisa ambiental em torno de três disciplinas: engenharias (notadamente sanitária), biologia e química, com 95,9 \% do total. As áreas econômica, social e política, por exemplo, não aparecem nas estatísticas. Quanto à participação relativa das pesquisas sobre meio ambiente e recursos naturais no conjunto das pesquisas registradas no Selap/CNPq, em 1985, tem-se um índice de aproximadamente $1,6 \%$. O percentual de pesquisadores vinculados a tais pesquisas era de $3,78 \%$.

Em 2003, já com um quadro geral de referência e demandas bem mais complexo, o panorama é diferente. Dentre as mais de 180 mil teses disponíveis em resumo no banco de dados da Capes (fonte: www.capes.gov.br), os mais de 468 mil pesquisadores cadastrados na Plataforma Lattes de curricula vitarum (http://lattes.cnpq.br, em 20/ 11/2004) e os cerca de 15 mil grupos de pesquisa inscritos no cadastro do CNPq, já se percebe uma partilha bem eqüitativa, em termos de distribuição por áreas do conhecimento,

1 Não se pretende aqui polemizar em torno da vinculação da temática ambiental a campos disciplinares consagrados na academia. Arquitetos lidam com ambiente, como espaço construído; sociólogos se interessam pelo ambiente social e cultural; biólogos trabalham com a noção de ecologia, ao tratar de ambientes onde se dá a interação natureza e alguma espécie em particular, seja ela da fauna ou da flora. Todas as contribuições das diferentes disciplinas com conhecimentos que convirjam para o trato da questão ambiental são condições necessárias, mas não suficientes, para o estudo do ambiente como espaço de enfrentamento do desafio do desenvolvimento sustentável. 
das vinculações a temas ambientais. $\mathrm{O}$ conjunto das $\mathrm{Hu}-$ manidades, aliás, começa a despontar como o mais presente.

Não há dúvida quanto ao fato de que meio ambiente, biodiversidade, desenvolvimento sustentável e recursos naturais são questões que hoje se expressam em quase todos os campos do saber (ver quadro 1).

No total, agregando-se as referências às quatro palavras-chaves pesquisadas (meio ambiente, biodiversidade, desenvolvimento sustentável e recursos naturais), tem-se:

Ciências Agrárias - 13,7\%

Ciências Biológicas - 21,7\%

Ciências da Saúde - 2,4\%

Ciências Exatas e da Terra - 15,8 \%

Ciências Humanas - 15,7\%

Ciências Sociais Aplicadas - $20 \%$

Engenharias - 11,6\%

A Conferência Rio-92 (Eco 92) e o clima de mobilização e esclarecimentos sobre a questão ambiental foram dinamizadores do interesse da sociedade em geral e da Universidade em particular - em direção a tais temas. No caso da mídia, que tem papel crucial na formação e na mobilização de opinião pública, o período que antecede aquele grande evento foi fortemente marcado pelo crescimento qualitativo e quantitativo do espaço dedicado aos grandes problemas ambientais do planeta, tanto no âmbito das diferentes formas de poluição industrial ou da degradação das florestas, quanto nos efeitos sobre o clima e os recursos hídricos. Vale assinalar que, após a Conferência do Rio, a mídia brasileira foi paulatinamente reduzindo o espaço dedicado aos temas ambientais.

No caso da Universidade, embora a questão ambiental tenha marcado fortemente os debates desde os anos $1960-$ seja pelos alertas neo-malthusianos, seja por propostas de mudanças nos paradigmas industriais - um duplo movimento passou a se dar na última década do século XX: a ambientalização das disciplinas e a interdisciplinarização do ambiente.

Esse duplo movimento implica dois tipos de arranjos institucionais - sendo um bem mais simples que o outro - que tendem a ser complementares:

- O primeiro se dá com a inserção da questão ambiental como foco de interesse, marcando novas linhas de pesquisa e áreas de concentração

QUADRO 1- GRUPOS DE PESQUISA CNPQ - LINHA DE PESQUISA/PALAVRA-CHAVE DA LINHA DE PESQUISA, POR GRANDES ÁREAS, EM 2002. CNPq's RESEARCH GROUPS - RESEARCH LINE / RESEARCH LINE KEY-WORD, PER LARGE AREAS, IN 2002.

\begin{tabular}{|c|c|c|c|c|}
\hline & $\begin{array}{l}\text { Desenvolvimento } \\
\text { Sustentável }(122) \%\end{array}$ & $\begin{array}{c}\text { Recursos } \\
\text { naturais } \\
(85) \%\end{array}$ & $\begin{array}{l}\text { Meio ambiente } \\
(409) \%\end{array}$ & $\begin{array}{l}\text { Biodiversidade } \\
\quad(162) \%\end{array}$ \\
\hline $\begin{array}{l}\text { Ciências } \\
\text { Agrárias }\end{array}$ & 5,74 & 40,00 & 6,85 & 18,52 \\
\hline $\begin{array}{l}\text { Ciências } \\
\text { Biológicas }\end{array}$ & 11,48 & 7,06 & 10,27 & 66,05 \\
\hline $\begin{array}{l}\text { Ciências da } \\
\text { Saúde }\end{array}$ & 1,64 & 1,18 & 3,42 & 1,23 \\
\hline $\begin{array}{l}\text { Ciências Exatas } \\
\text { e da Terra }\end{array}$ & 4,92 & 20,00 & 20,54 & 9,88 \\
\hline $\begin{array}{l}\text { Ciências } \\
\text { Humanas }\end{array}$ & 23,77 & 11,76 & 19,8 & 1,23 \\
\hline $\begin{array}{l}\text { Ciências Sociais } \\
\text { Aplicadas }\end{array}$ & 36,07 & 17,65 & 22,74 & 2,47 \\
\hline Engenharias & 16,39 & 2,353 & 16,38 & 0,62 \\
\hline
\end{tabular}

FONTE: WWW.CNPq.BR 
BURSZTYN, M. Meio ambiente e interdisciplinaridade: desafios ao mundo acadêmico

(nos departamentos disciplinares): economia ambiental, sociologia ambiental, direito ambiental, geologia ambiental, engenharia ambiental, educação ambiental, química ambiental, história ambiental, além de uma mudança relativa no âmbito de outras disciplinas, com a consagração da ecologia na biologia ou da agroecologia na agronomia.

- O segundo consiste do surgimento de programas interdisciplinares, particularmente em nível de Pós-Graduação.

Esse segundo caso nos interessa, em particular, sua originalidade, pelos desafios que enfrenta e por seu papel como eventual modelo institucional.

\section{Originalidade}

Após décadas de especialização, fragmentação, compartimentalização e auto-enclausuramento das ciências disciplinarizadas, a questão ambiental suscita um movimento reverso de des-especialização. A própria natureza e complexidade dos problemas a serem tratados no universo dos temas ambientais - sinergias, objetos mutantes, abrangências, interesses envolvidos, superposição de diferentes escalas, revisão de paradigmas consagrados etc. exige que as competências a serem mobilizadas sejam amplas.

A originalidade se dá também pelo fato de que os novos programas interdisciplinares surgem na contra-mão da maré especializante, que marcou a pesquisa científica em geral e a Universidade em particular, por muitas décadas.

Evidentemente, seria necessário um aprendizado institucional para que tal movimento se desse.

No Brasil, o surgimento de programas de pós-graduação interdisciplinares em meio ambiente coincide com a maré de atenção que a questão ambiental passou a ter com a conclusão do Relatório Brundtland, que foi publicado em 1998. O primeiro curso com tal caráter surge na Universidade de São Paulo - o Procam, Programa de Ciências Ambientais - por volta de 1990. Em 1994, inicia-se o programa Meio Ambiente e Desenvolvimento, na Universidade Federal do Paraná. O programa de Desenvolvimento Sustentável da Universidade de Brasília foi criado em 1995.

Com cerca de 30 programas operando com credenciamento junto à Capes, em 2004, pode-se estabele- cer uma tipologia de processos de institucionalização de tais experiências, todas sui generis.

\section{Fórmula "bandeirante"}

O modelo USP, pioneiro, representa uma tentativa de estabelecimento de um ponto focal de interface de docentes e pesquisadores atuantes em torno do tema, com a criação de um mestrado. Em se tratando de uma universidade de grande prestígio nacional, com tradição de implantação de cursos que dificilmente são desclassificados ou mal classificados nos rankings acadêmicos, a opção parece ter sido a de criar o fato consumado, implantando o programa para depois obter o credenciamento.

A experiência levaria cerca de uma década para obter o reconhecimento pela Capes, acumulando um significativo contingente de egressos diplomados sem a devida homologação pelo Ministério da Educação. Em termos operacionais o Procam gravita em torno de um conjunto de professores, todos vinculados a outros departamentos, com uma coordenação que se alterna em termos de perfil: ora das humanas, ora das naturais ou biológicas.

\section{Fórmula "na moita"}

O modelo UFPR tem também uma característica singular. Surgiu como programa de doutorado, sem ter passado previamente pela experiência de mestrado. Valendo-se de docentes com dupla lotação, constituiu um espaço interdisciplinar quase marginal dentro de um complexo organograma de cursos, típico das grandes universidades brasileiras. O impacto, em termos de visibilidade, foi relativamente pequeno, no curto prazo, fato que deve ter servido como anteparo a pressões opositoras por parte dos departamentos institucionalizados a mais tempo.

A arrancada inicial do programa foi facilitada também por uma providencial teia de cooperação internacional, com a França, que serviu ao mesmo tempo como legitimadora e provedora de meios (inclusive humanos). A classificação do Programa Meio Ambiente e Desenvolvimento - MAD da UFPR como Cátedra de Desenvolvimento Sustentável da Unesco foi um importante fator de apoio e consolidação. O fato de abrir turmas apenas a cada dois anos, em escala relativamente reduzida para ser notada no conjunto das ações da universidade, também contribuiu para 
a afirmação do programa. Passados poucos anos, e apesar das dificuldades em se negociar a dupla lotação dos docentes, o programa fincou raízes. Nasceu e cresceu de forma discreta e irreversível.

\section{Fórmula "decolagem sem retorno"}

O programa de Desenvolvimento Sustentável da UnB surge inicialmente com um doutorado em moldes semelhantes ao da UFPR, embora com turmas anuais. Contrariando pressões corporativas de forças departamentais da universidade, o programa foi criado graças a três circunstâncias: apoio da reitoria, reconhecimento prévio pela Capes e obtenção de apoio financeiro do programa PADCT, do CNPq.

Em pouco tempo, surgiram oposições por parte dos departamentos de origem dos docentes, que não admitiam a perda parcial de seus quadros, sem a devida substituição por novos contratados, em momento de total fechamento da oferta de vagas com concurso para professores. A opção adotada foi a da fuga para frente, aumentando o ingresso de alunos, a magnitude da comunidade envolvida e as ações visíveis. Para se tornar viável, o programa optou por mostrar resultados notáveis já no curto prazo e em volume crescente, de forma a assegurar a sua irreversibilidade.

Tendo iniciado apenas com o doutorado, logo o programa criou mais três cursos: mestrados acadêmico e profissionalizante em política e gestão ambiental e mestrado profissionalizante em política e gestão de ciência e tecnologia. A magnitude do programa, que cresceu rápida e audaciosamente, adquirindo visibilidade, é um dos fatores que explica sua legitimação.

\section{Fórmula "unidos venceremos"}

Desde o início da década de 1990, um conjunto de universidades da região nordeste lutava para instituir um programa em rede. É um caso típico de iniciativa "avant la lettre", pois só mais tarde o conceito de rede se consagraria. Buscando uma união que os tornasse suficientemente fortes para o credenciamento na Capes e valendo-se das vantagens comparativas de cada instituição participante, montou-se um programa de mestrado inter-universidades, o Prodema - Programa de Desenvolvimento e Meio Ambiente: UFAL (Maceió), UFSE (Aracajú), UERN (Mossoró),
UFPB (João Pessoa), UFC (Fortaleza), UESC (Ilhéus) e UFRPE (Recife).

O grupo de universidades estabeleceu uma certa cultura coletiva, mas com vinculações mais formais do que efetivas. Embora operando oficialmente em rede, usando todas a mesma denominação, a prática tem sido de relativa autonomia, em grande parte pelo fato de que o credenciamento e a avaliação pela Capes é dada de forma individualizada.

\section{Fórmula “de transição”}

É o caso do Núcleo de Altos Estudos da Amazônia, da UFPA. Após cerca de duas décadas de funcionamento, estabelecendo-se como centro de referência na região, o programa se desloca da subárea de Sociologia, na Capes, para a Multidisciplinar. Por ter tido uma construção institucional solidificada ao longo do tempo numa universidade em que as pressões departamentais eram relativamente menos limitantes, a transição do NAEA para a vinculação socioambiental não pode ser qualificada como traumática.

\section{Fórmula "parto natural"}

Um conjunto crescente de programas foi surgindo, a partir do final da década de 1990, tanto em universidades públicas como privadas, atendendo a um movimento natural de atendimento a demandas. O notável crescimento da procura por formação em temas ambientais, por si só, serviu de estímulo a que universidades mais jovens e menos marcadas por tensões corporativas internas fossem instituindo os seus programas interdisciplinares. Tais cursos geralmente obedecem a características locais e regionais, sintonizando em problemas mais específicos. Nesse caso "o parto é natural", sem traumas maiores, além da dificuldade de credenciamento na Capes. Podem ser citados como exemplo dessa fórmula, cursos como o da UFPE e o da UFAM.

\section{Desafios}

O modus operandi dos programas de Pós-Graduação interdisciplinares em meio ambiente, qualquer que seja o modo de institucionalização que seguiu, implica dificuldades e obstáculos, tanto em nível da legitimação no âmbi- 
to da própria universidade em que se situam, quanto em termos de credenciamento e avaliação pela Capes. É possível classificar os desafios enfrentados nas tentativas de organizar comunidades universitárias em torno da questão ambiental como um conjunto de síndromes. São síndromes, pois além de serem patologias, têm tipicidades e são recorrentes.

\section{A sindrome da estigmatização como generalidade}

As atividades desenvolvidas em programas interdisciplinares, por reunir pesquisadores de diferentes formações e habituados a manejar métodos e jargões bem particulares, geram práticas que permitem diálogo entre diferentes disciplinas. Para tanto, não se pode adotar linguagens e códigos comunicação que sejam de difícil entendimento aos não-iniciados. Disso resulta que os produtos interdisciplinares tendem a ser de fácil entendimento.

Como conseqüência, surge uma imagem de falta de foco, pouca profundidade, convivência com diferentes, linguagem pouco hermética, enfim, como ciência, algo a não ser "levado a sério" (como se ser sério fosse resultado de ser sisudo; e ser rigoroso fosse ser de difícil entendimento), uma ciência menor ou uma não-ciência.

\section{A sindrome da recusa da alteridade}

Esta se define pela metáfora de muitos ratos em um espaço limitado, como na psicologia comportamental.

A crise financeira vivida pelas universidades provoca reações corporativas e egoístas, de defesa dos espaços ocupados pelas atividades e unidades consolidadas. $\mathrm{O}$ espaço para surgimento de novidades fica reduzido, em função da falta de meios (recursos humanos e financeiros). $\mathrm{O}$ debate nos colegiados acadêmicos pende para uma rejeição às propostas de criação de novos cursos, a menos que novos recursos sejam adicionados aos orçamentos, o que não vêm ocorrendo.

A tendência é que propostas de iniciativas inovadoras que resultem na institucionalização de novas unidades acadêmicas sejam objeto de uma dupla reação: a desqualificação (principalmente quando não há aporte direto de apoios financeiros) ou a tentativa de absorção e enquadramento em alguma unidade estabelecida (quando se trata de projetos dispondo de financiamento assegurado).
A recusa do novo - do reconhecimento do "outro" é, nesse sentido, uma reação de defesa do velho.

\section{A síndrome da nobreza arruinada}

A Universidade pública enfrenta várias carências, mas não perde a pose e recusa o novo. Acostumada a ser mantida com verbas públicas, que sempre asseguraram a manutenção de suas atividades e o pagamento de seu pessoal, a Universidade brasileira cristalizou uma cultura de sempre esperar que o Estado seja o provedor de suas iniciativas a ações. Isso é particularmente notável em programas mais antigos e consolidados. Como o recrutamento dos membros de colegiados decisores, tanto internamente a cada instituição, quanto nas agências de fomento, se dá por critérios de reconhecimento e consagração, é evidente que os membros de cursos mais antigos são sempre presença majoritária. Daí, um círculo vicioso se forma: as referências para análise dos programas novos acabam sendo as do universo daqueles mais antigos.

Ora, os últimos anos têm mostrado que a emergência de novos cursos se dá na contra-corrente do empobrecimento da Universidade. Um confronto entre exigências usuais e possibilidades efetivas se estabelece, então: reza a prática da avaliação que os programas devem dispor de um certo número de docentes enquadrados na categoria NRD6 , ou seja, vinculados contratualmente e dedicados em tempo majoritário ao curso em questão. Mas se os quadros das universidades públicas não se reproduzem nem se renovam, então a possibilidade de surgimento de novos cursos fica comprometida. A não ser que aumente a carga horária dos docentes ou que os programas mais recentes utilizem expedientes de aliciamento de seus membros, mediante "fagocitose" intra-institucional. Os mecanismos de acompanhamento e avaliação parecem desconhecer tais limitações, recomendando aos cursos que contratem novos docentes. É como a velha nobreza, que mesmo arruinada não perde a majestade. Marie Antoinette, quando informada de que o povo não tinha pão, recomendou que ele comesse brioche!

No contexto vigente, as exigências feitas vão no sentido de se manter o modelo tradicional de engajamento de docentes, mediante novos concursos que não acontecem por falta de orçamento e de autorização (no caso das universidades federais). Desprezam-se, assim, fórmulas inovadoras, como a agregação de colaboradores de longa du- 
ração e em dedicação exclusiva, mas sem vínculo contratual (como bolsistas, aposentados, contratados por projetos ou cooperantes internacionais). As instituições privadas, que têm maior flexibilidade para contratar (e também para demitir), sempre que seja conveniente, acabam desfrutando de situação de vantagem. Mas, ainda assim, na Pós-Graduação, as universidades públicas são responsáveis por $92 \%$ dos cursos de doutorado e $84 \%$ dos de mestrado.

\section{A sindrome do bastardo}

É típica da crise de identidade. Resulta do fato de que os programas interdisciplinares são formados por docentes e pesquisadores de origens disciplinares variadas, com vinculações funcionais a departamentos diversos e com dificuldades de enquadramento de seus trabalhos. ${ }^{2}$

Como bastardos, surge a dúvida: quem sou? Qual o meu endereço? Qual o meu sobrenome? A quem devo me dirigir? Enfim, existo (porque penso) mas quem são meu pai e minha mãe?

\section{A sindrome da avaliação pelos ímpares}

Em 2004, a Capes avaliou a totalidade dos 2.861 cursos de mestrado e doutorado credenciados no Brasil. Desse total, apenas 111 - os que se enquadram na área denominada multidisciplinar e ensino de ciências - não foram analisados por comissões de avaliação composta exclusivamente por pares.

Em 1999, a Capes criou uma comissão especial para avaliar cursos que não se enquadravam em nenhuma das 8 grandes áreas e 44 subáreas do conhecimento que compõem a estrutura do sistema de avaliação. A idéia foi abrir um espaço para o crescente número de programas que fugiam à divisão tradicional em compartimentos ou que não eram assimilados ou acolhidos pelas comissões para as quais eram enviados. Ou seja, na avaliação pelos pares (peer evaluation), alguns cursos não eram identificados como partes integrantes. A nova comissão de área então criada reuniria o conjunto de "multi"disciplinares e um grupo de cursos que, pela sua natureza, é de enquadramento problemático nos campos disciplinares: o ensino de ciências, que não trata de ciência pura nem apenas de educação.

Entre 1999 e 2003, a evolução do número de programas avaliados pela área multidisciplinar se deu em ritmo intenso: 44 em 1999, 57 em 2000, 70 em 2001, 85 em 2002

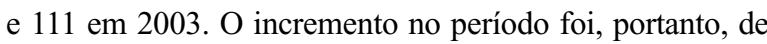
$152 \%$, enquanto o aumento no número de programas credenciados pela Capes, em todas as áreas, foi de $27 \%$. Há que se salientar que o subgrupo de cursos que se enquadram na temática ambiental (que é classificada junto com os temas agrários) teve crescimento mais que proporcional em relação ao conjunto dos multidisciplinares: de $25 \%$ do total, na avaliação de 2001, passou para 35\% em 2002.

Algumas características operacionais da comissão que avalia tais cursos merecem ser aqui consideradas. Em primeiro lugar, sobressai a constatação de que a demanda por credenciamento de programas tem sido intensa, seja pela auto-identificação por parte das instituições envolvidas, seja pela decisão de outras comissões de área, que avaliam a maior pertinência de remeter alguns cursos para a área multidisciplinar. Por conta disso, a comissão de avaliação opera com sobrecarga de projetos analisados, nem sempre aceitando como de sua alçada as propostas recebidas. Assim, dos 140 novos pedidos de credenciamento até 2003 , entre 30 e 40 foram enviados para outras áreas, entre 60 e 70 foram recusados e apenas 40 foram aprovados. Um índice de aceitação abaixo dos $30 \%$ reflete, sem dúvida, um gargalo que não encontra paralelo em outras áreas.

Em segundo lugar, há uma identidade, por parte dos avaliadores de cursos submetidos à área multidisciplinar, de que sua função é de "incubadora" de cursos a serem devidamente orientados, em seu nascimento, para depois remeter a uma área consolidada. Nesse sentido, a avaliação seria também um processo de modelagem e direcionamento disciplinar. Isso fica definido no próprio Documento da Área Multidisciplinar, de 2001 (www.capes.gov.br): "um substancial número de cursos são transitórios no comitê interdisciplinar, devendo ser incorporados a outros comitês (...)" [sic].

Vale aqui evocar Protágoras (filósofo grego do século V a.C.): "o Homem é a medida de todas as coisas". Por-

2 Mesmo considerando que a Capes instituiu uma área específica para tratar dos programas multidisciplinares, os profissionais vinculados a tais práticas têm dificuldades em veicular suas atividades e produção enquanto tal. A Plataforma Lattes não prevê esse tipo de vinculação, ficando a cargo de cada pesquisador identificar-se com alguma disciplina. Da mesma forma, os ritos de enquadramento no CNPq não consideram a interdisciplinaridade. A saída usual, para estes casos, é o enquadramento na opção "outros" dentro de alguma disciplina. 
BURSZTYN, M. Meio ambiente e interdisciplinaridade: desafios ao mundo acadêmico

tanto, conhecemos o mundo com "nossos" olhares, e acabamos avaliando "eles" como se fossem "eu". Na avaliação da interdisciplianridade, ainda não se formou um "nós".

\section{A sindrome da tutela}

A idéia de tratar os programas submetidos ao comitê multidisciplinar como iniciativas a serem incubadas se traduz inevitavelmente em ação de tutela. É como se os cursos avaliados fossem infantes, merecedores de cuidados especiais. Nesse sentido, não são e não conseguem ser vistos como adultos, mesmo quando amadurecem.

Por conta disso, a distribuição estatística dos conceitos atribuídos aos mesmos, embora formem uma curva normal, como a totalidade dos avaliados pela Capes, têm como patamar superior o conceito 5. O grupo dos multidisiciplinares é o único, dentre as 44 subáreas de avaliação, que não registra cursos com conceitos 6 e 7. A moda estatística, aliás, ficou em 3 , que é o patamar mínimo para o credenciamento.

Como infantes e incubados, são tutelados em estreita vigilância, por parte de um comitê formado por membros que, em seu conjunto, têm pouca vivência em programas que fogem ao caráter disciplinar. Dos 23 membros da comissão que avaliou os cursos multidisciplinares em 2004, apenas 8 eram docentes efetivamente vinculados a programas avaliados na área. Os demais, eram de cursos submetidos à avaliação disciplinar em outros comitês. Na avaliação de 2001, o processo foi ainda mais marcadamente tutelado: apenas 2, dos 17 membros, eram docentes (NRD6) de cursos multidisciplinares.

É nesse contexto que a síndrome da avaliação pelos ímpares - deformação da consagrada avaliação pelos pares - se expressa em tratamento diferenciado aos programas que "desviam" da lógica tradicional do enquadramento disciplinar.

\section{A síndrome do Narciso ou das métricas externas}

Como corolário da avaliação por ímpares, os critérios que instruem as medições de qualidade dos resultados são fortemente influenciados pelas idiossincrasias das áreas de vinculação dos avaliadores.

Mal entendida como uma área que tenha suas próprias características e identidades, a interdisciplinaridade acaba sendo objeto de uma amálgama das expectativas dos diferentes membros do comitê. Isso se reflete tanto no peso relativo atribuído aos veículos de divulgação dos resultados, quanto na própria análise das grades curriculares.

Como Narciso, que (parodiando o poeta) "acha feio tudo o que não é espelho", os avaliadores tendem a valorizar mais as interfaces dos programas analisados com suas identidades disciplinares, rechaçando as outras dimensões abordadas. No caso das métricas que instruem a pontuação da produção acadêmica, a avaliação por ímpares resulta em subvaloração de resultados que podem ser notáveis. Um exemplo é a conhecida diferença entre as humanidades e as ciências naturais e exatas, quanto ao tipo de publicação visada para difundir resultados. $\mathrm{O}$ primeiro grupo tende para livros, enquanto o segundo procura mais as revistas especializadas. Isso não implica, evidentemente, que um seja melhor ou pior que o outro; apenas, que são de natureza diferenciada. Como cada uma dessas áreas é avaliada pelos seus próprios pares, a diferenciação não se traduz em estranhamento. Mas quando cursos interdisciplinares são avaliados por critérios e práticas típicas de disciplinas específicas, o resultado é fatalmente injusto, com cobranças muitas vezes indevidas e desconsideração de resultados relevantes.

\section{A síndrome da "gaiola das loucas"}

O ambiente universitário é um território onde deve florescer a criatividade, a imaginação e a ousadia. Iniciativas inovadoras são parte do quotidiano acadêmico. Entretanto, em meio à criatividade há espaço para que aflorem comportamentos e iniciativas excêntricas ou que se desenvolvam trabalhos de pouca relevância. A instituição do Prêmio Ig-Nobel, uma bem humorada paródia ao consagrado Nobel, promovida por pesquisadores da prestigiosa Universidade de Harvard, é um testemunho do grau de liberdade que a pesquisa acadêmica tem, podendo centrarse em focos duvidosos ou absolutamente inúteis. A publicação dos Anais da Pesquisa Improvável (http:// www.improb.com) é um rico manancial de tais atividades.

O surgimento de programas interdisciplinares, sobretudo quando visados por expectativas transdisciplinares, se converte em lócus de interesse e de identificação como possibilidade de acolhimento das excentricidades que afloram na academia. Isso pode se dar tanto pela indução 
por parte dos "pares" a que pesquisadores que não se ajustem a certo clima departamental sejam remetidos aos programas mais "ecléticos", quanto pela própria iniciativa individual.

Vale assinalar, portanto, que é relevante evitar a imagem de "hospício acadêmico" que resulta do estigma que associa interdisciplinaridade a excentricidade.

\section{A sindrome NRA}

Como decorrência do que foi apresentado acima, verifica-se também que há uma certa tendência a que sejam remetidos aos programas interdisciplinares os resíduos dos enquadramentos nas áreas de concentração e linhas de pesquisa de departamentos. O desajuste de enquadramentos vem resultando em identificação dos cursos interdisciplinares como depositários de objetos de interesse que fogem às classificações. É como se fossem a opção "nenhuma das respostas anteriores".

Se tal síndrome persiste e ganha consistência, o risco de crise de identidade dos programas em questão é grande.

\section{Conclusão: em busca de um modelo institucional}

A Universidade está em crise. Isso parece ser o ponto que reúne maior grau de consenso entre os diferentes protagonistas de sua missão. É uma crise, pois não consegue mais ser como vinha sendo e não consegue também se tornar outra coisa. É uma crise existencial que também se reflete no seu devir. Portanto, é hora de buscar alternativas.

É nesse sentido que os processos de institucionalização que vêm sendo protagonizados pelos cursos que gravitam em torno da área mutidisciplinar devem ser objeto de uma acurada avaliação: de trajetória, mas também enquanto modelos de implantação. Nascidos na adversidade (de legitimação institucional e de dotação de meios) são experiências notáveis de um metabolismo inovador. Não só por inovarem em matéria de modus operandi de lidar com desafiantes e complexas questões da atualidade, são também estruturas criativas em sua organização burocrática.

Os arranjos que vêm sendo criados nas experiências interdisciplinares devem, portanto, ser avaliados como fórmulas a serem exploradas.

Alguns fatos podem ser norteadores, se se quer avançar na reflexão sobre o desenho possível e desejável, a ser assumido pela Universidade pós-crise:

- A área "multidisciplinar" na Capes é a que mais cresce, mesmo em considerando-se que o sistema de Pós-Graduação brasileiro como um todo vem crescendo em ritmo acelerado.

- As demandas por formação em programas de PósGraduação em meio ambiente não cessam de crescer.

- Alguns programas já se consolidaram após 10 anos.

- Surge uma cultura de "campo", no sentido proposto por Bourdieu. ${ }^{3}$ Mas diferentemente de outros campos, há amplo espaço para solidariedade, com menos competição. A colaboração tem sido um marco nas relações entre os grupos que atuam na área.

- Há uma razoável auto-suficiência, por se tratar de programas nascidos na crise.

- O instituto da dupla-lotação propicia uma organicidade, numa Universidade fragmentada. O "modelo em estrela" (um núcleo com vários satélites) se revela positivo, pois permite uma militância departamental a cada docente e pesquisador, ao mesmo tempo em que abre espaço para uma convivência interdisciplinar. Ao contrário do que podem se opor os departamentos de origem, essa prática resulta em importante aporte aos mesmos, pois traz insumos que instigam e enriquecem suas rotinas.

- Há uma alta propensão a fazer ponte entre teoria e prática e a resgatar o elo perdido da função extensão da Universidade.

3 O campo é o espaço onde "cada um dos agentes investe a força (o capital) que adquiriu pelas lutas anteriores, em estratégias que dependem, quanto à orientação, da posição desse agente nas relações de força, isto é, do seu capital específico" (BOURDIEU,1990, p. 171-172). Nesse contexto vanguardas renascentes se opõem a vanguardas consagradas. "Um campo se define através dos objetos de disputas e dos interesses específicos que são irredutíveis aos objetos de disputas e aos interesses próprios de outros campos e que não são percebidos por quem não foi formado para entrar nesse campo" (BOURDIEU, 1983, p. 90). 
BURSZTYN, M. Meio ambiente e interdisciplinaridade: desafios ao mundo acadêmico

Enfim, valendo-se da imagem proposta por Castells (1999) para a estruturação do Estado na era pós-neoliberal - o Estado-Rede - a Universidade pós-crise pode vir a ser uma Universidade-Rede. No lugar da compartimentalização em departamentos estanques, que não se comunicam e perdem a capacidade de lidar com alguns desafios da modernidade, que exigem soluções complexas e interdisciplinares, a operação em rede pode tornar viável um movimento no sentido da integração.

É nesse sentido que, voltando aos dois movimentos (ambientalização das disciplinas e interdisciplinarização do ambiente), é preciso não sucumbir às pressões para se "disciplinarizar o ambiente".

\section{REFERENCIAS}

BOURDIEU, Pierre. O campo intelectual: um mundo à parte. In: . (Org.). Coisas ditas. São Paulo: Brasiliense, 1990.

. Algumas propriedades do campo. In: . (Org.). Questões de Sociologia. Rio de Janeiro: Marco Zero, 1983.

BUARQUE, Cristovam. Universidade ligada. In: MORHY, L. (Org.). Universidade em questão. Brasília: UnB, 2004.

BURSZTYN, Marcel. Ciência, tecnologia e pesquisa ambiental na Universidade Brasileira: dilemas e potencialidades. In:
SEMINÁRIO UNIVERSIDADE DE MEIO AMBIENTE DOCUMENTOS BÁSICOS, 1990, Brasília, Ibama.

Introdução. In: (Org.). Ciência, ética e sustenta-bilidade - desafios ao novo século. São Paulo: Cortez/ Unesco, 2001.

CASTELLS, Manuel. A sociedade em rede. São Paulo: Paz e Terra, 1999, v. 1.

PASSET, René. L'Illusion Neo-libérale. Paris: Fayard, 2000. 